\title{
GENDER, LOCUS OF CONTROL AND SMOKING HABITS OF UNDERGRADUATE STUDENTS
}

\author{
${ }^{1}$ Gboyega E. Abikoye \& ${ }^{2}$ Adetutu Fusigboye \\ ${ }^{1}$ Department of Behavioural Studies, Redeemer's University, \\ Redemption City, Mowe, Nigeria. \\ ${ }^{2}$ Department of Psychology, Olabisi Onabanjo University, Ago-Iwoye, Nigeria.
}

\begin{abstract}
Health psychologists believe that a significant proportion of human morbidity and mortality could be significantly reduced and humans' quality of life greatly enhanced if people could be helped to correct their health-impairing habits and behaviours, such as smoking and other forms of substance abuse. The present study investigated the influence of gender and locus of control on smoking habit of 230 smoking student-patrons of two relaxation centers in Ago-Iwoye, the host community of Olabisi Onabanjo University. Participants were 137 (59.6\%) male and 93 (40.4\%) female students with a mean age of $24.93(\mathrm{SD}=4.58)$. Relevant data were collected using snowballing technique over an eight-week period, with a standardized, three-sectioned questionnaire. Results showed that locus of control had a significant influence on smoking habit $\{\mathrm{t}(2,226)=21.21$, $p<0.05\}$, with internals reporting significantly and relatively higher on smoking habits than externals. Results further showed that there was no significant difference of gender on smoking habit among undergraduate students $\{\mathrm{t}(2,228)=3.83, p>0.05\}$. These and other findings in the study were discussed and their implications for intervention programmes on smoking reduction or (and) cessation were highlighted.
\end{abstract}

KEY Words: Smoking habits, student-patrons, locus of control, gender, Ago-Iwoye

\section{INTRODUCTION}

According to the World Health Organization's Report on the Global Tobacco Epidemic (WHO, 2008), smoking is the single most preventable cause of death in the world. In 2008, tobacco smoking was estimated to have killed more than five million people - more than tuberculosis, HIV/AIDS and malaria combined; and by 2030 , it is projected that the death toll will exceed eight million a year (WHO, 2008). The report further highlighted an obvious but commonly-overlooked fact: tobacco is the only legal consumer product that can harm everyone exposed to it - and it kills up to half of those who use it as intended (WHO, 2008). Yet, tobacco use is common throughout the world due to many factors including low prices, aggressive and widespread marketing, lack of awareness about its dangers, inconsistent public policies

Corresponding author: Dr. Gboyega E. Abikoye, Department of Behavioural Studies, Redeemer's University, Redemption City, Mowe, Nigeria. E-mail: ageabikoye@yahoo.com; Telephone: +234-8055065741. 
against its use, person-related factors, among other factors (Center for Disease Control and Prevention: CDC, 2010a; Gilma \& Xun, 2004; WHO, 2008; Wingand, 2006).

Tobacco smoking is the practice where tobacco is burned and the vapors either tasted or inhaled. Smoking is the most common method of consuming tobacco, and tobacco is the most common substance smoked. The vapors in a burning tobacco are inhaled and the active substances absorbed through the alveoli in the lungs (Gilman \& Xun, 2004). The active substances trigger chemical reactions in nerve endings, which heightens heart rate, memory, alertness (Parrott \& Winder, 1989), and reaction time (Parkin, Fairweather, Shansi, Stanley \& Hindmarch, 1998). Dopamine and later endorphins are released, which are often associated with pleasure (Gilman \& Xun, 2004). As of 2000 , smoking is practiced by some 1.22 billion people.

Because they are engaging in an activity that has negative effects on health, people who smoke tend to rationalize their behavior. In other words, they develop convincing, if not necessarily logical reasons why smoking is acceptable for them to do. For example, a smoker could justify his or her behavior by concluding that everyone dies and so cigarettes do not actually change anything. Or a person could believe that smoking relieves stress or has other benefits that justify its risks. The reasons given by smokers for this activity are broadly categorized as addictive smoking, pleasure from smoking, tension reduction/relaxation, social smoking, stimulation, and habit/automatism (Berlin, Singleton, Pedarriosse, Lancrenon, Rames, Aubin, \& Niaura, 2003). Researchers have also reported that some people use smoking for the pleasure of handling the cigarette (Berlin et al., 2003; Wang, Yu and Zhu, 1994).

It is now widely recognized that cigarette smoking is harmful to health and that cessation would have major health benefit for smokers and people around them (Melby, Conger \& Conger, 1993; Ogden, 2003). Smoking causes cancer, heart disease, stroke, and lung diseases (including emphysema, bronchitis, and chronic airway obstruction) (CDC, 2008). For every person who dies from a smoking-related disease, 20 more people suffer with at least one serious illness from smoking (CDC, 2008). Worldwide, tobacco use causes more than 5 million deaths per year, and current trends show that tobacco use will cause more than 8 million deaths annually by 2030 (WHO, 2008). In the United States, tobacco use is responsible for about one in five deaths annually or about 443,000 deaths per year; and an estimated 49,000 of these tobacco-related deaths are the result of secondhand smoke exposure (CDC, 2008). On average, smokers die 13 to 14 years earlier than nonsmokers (CDC, 2002).

Undergraduates who smoke persistently face an array of possible consequences raging from lowered commitment to education, declining grades, increased potential for dropout and high truancy rate (Hawkins, Catalano $\&$ Miller, 1992). Other risks associated with tobacco use among the youths include highrisk sexual behavior, use of alcohol and other drugs (CDC, 2007). In addition, prevalence of depression, failure to thrive, apathy and withdrawal have been attributed to smoking among students (Glantz et al., 1995; Hawkins et al., 1992; Ogden, 2003; Shamsuddin \& AbdulHan, 2000). Furthermore, siblings and parent are also affected profoundly by undergraduate involvement in smoking. This may drain family financial and emotional resources (Shamsuddin \& Abdul-Han, 2000).

Researchers have consistently placed the explanation of smoking and other drug-related behaviours mainly in the psychological domain (Tyas \& Pederson, 1998). One psychological factor that has been implicated in the area of substance use and abuse and other health-related issues is locus of control. Locus of control is a concept which explores individuals' placement of responsibility, choice, and control of events in their lives (Lau, 1982). It distinguishes between two common approaches, which place the actual control either internally or externally. The person with an internal locus of control believes that he/ she is responsible for his or her life behaviors and action. Internals also believe that they possess the ability to control 
events in their lives. Externals (individuals who place controls and responsibilities in their lives externally) believe that influences outside of themselves are responsible for controlling their lives' circumstances. The study of smoking and locus of control has produced mixed results. More internal health beliefs have been associated with both smoking and not smoking in the general population (Tyas \& Pederson, 1998; Danklefs, 2004). However, tobacco-using adolescents have been found to have more external locus compared with non-users (Booth-Butterfield, Anderson, \& Booth-Butterfield, 2000; Hogson, 2001). In order to fully understand tobacco smoking among undergraduate students of Nigerian universities and to plan effective intervention programmes, it will be useful to consider the individual differences of locus of control because this factor represents an important individual characteristic regarding perceptions of contingencies.

There is empirical evidence which suggests that male students are more likely than their female counterparts to turn to smoking in attempting to cope with stress or in handling negative feeling (Hawkins et al., 1992; Santi, Best, \& Brown, 1990; Shamsuddin \& AbdulHan, 2000). Smoking is generally five times higher among men than women (Guindon \& Boisclair, 2003); however, the gender gap declines with younger age (WHO, 2001; CDC, 2001). In developed countries smoking rates for men have peaked and have begun to decline, however for women they continue to climb (Peto, Lopez, Boreham, Thun, 2006). As of 2002, about twenty percent of youths aged 13-15year smoke worldwide (WHO, 2002).

Despite the serious detrimental effects of smoking on the individual smoker, his or her family, friends, colleagues and the society at large, smoking tends to be on the increase, especially among university students (Campaign for Tobacco-Free Kids, 2009; CDC, 2010a). A visit to most relaxation centers in the host communities of many non-residential universities would reveal scenes of wanton and unbridled smoking and reckless behaviour among student-patrons of such centers. The trend appears to be on the increase because of a desire to 'belong' to the 'special guys' around. This trend is consistent with findings in the Western world (e.g. CDC, 2010b) that cigarette smoking is almost always initiated and established during adolescence and that more than $80 \%$ of adult smokers in the United States begin smoking before 18 years of age. Also, each day in the United States, approximately 3,450 young people between 12 and 17 years of age smoke their first cigarette, and an estimated 850 youth become daily cigarette smokers (Johnston, O'Malley, Bachman, \& Schulenberg, 2009; CDC, 2010a).

The problem of early smoking among youths is not new. In the early 1990s, Stanton found that most smokers begin during adolescence or early adulthood and that smoking has elements of risk-taking and rebellion, coupled with the presence of high-status models and peers, which often appeal to young people (Stanton, 1992). But while researchers and stakeholders in the developed countries have been making concerted efforts to tackle the problem, the scenario in the developing world, especially in Nigeria, has been that of indifference, a situation that is capable of causing devastation of huge proportion if left unaddressed.

The purpose of the present study was to investigate smoking habits of selected undergraduate students of a non-residential Nigerian university: patterns of smoking, types of substance being smoked, onset of smoking, gender differences and the role of locus of control in smoking habits. An understanding of these would not only serve the purpose of sensitizing stakeholders to the extent of the problem but would also be useful in designing smoking cessation/reduction intervention strategies among this at-risk population. Specifically, we hypothesized that students with internal locus of control would report more smoking habits than those with external locus of control. We also hypothesized that male undergraduate students would report more smoking habits than their female students. Finally, we tested the hypothesis that age would have a significant influence on smoking habits of undergraduate students. 


\section{METHOD}

\section{Participants}

Participants consisted of two hundred and thirty (230) undergraduate students of Olabisi Onabanjo University (formerly Ogun State University), Ago-Iwoye, selected using snowballing technique. Of the 230 participants, 137 (59.6\%) were males and $93(40.4 \%)$ were females. Participants mean age was 24.93 , $(\mathrm{SD}=4.58)$ with age range of 20 years to 30 years. In term of marital status, $187(81.3 \%)$ were singles, and 43 $(18.7 \%)$ were married. With regards to religion, 113 (49.1\%) were Christian, 95 (41.3\%) were muslims, 17 (7.4\%) traditionalists and $5(2.2 \%)$ reported unspecified others religions.

\section{Instrument}

A structured questionnaire was used for data collection. Demographic information was collected by requesting participants to state their age, sex, level of study in the university, marital status and religion. Most of these items were measured in an open-ended section of the questionnaire.

Locus of control was assesses with the Craig, Franklin and Andrew's (1984) Locus of Control scale. The 17-item Likert-type scale measures individuals' placement of responsibility, choice, and control of events in their lives. Respondents indicated the extent to which they agree or disagree with each of the items on the scale by choosing one of five options: 1 (Strongly Disagree), 2 (Disagree), 3 (Neutral), 4 (Agree) or 5 (Strongly Agree). High scores on the scale indicate tendency toward an internal locus of control while low scores indicate tendency toward an external locus of control. A coefficient internal consistency (using the Cronbach's alpha) of .79 was obtained for the scale in this study.

Smoking habit was assessed using the 18item Smoking Habit Scale (SHS) developed by the researchers. The instrument is a 5-point Likert-type scale which assesses the extent to which a person engage in habits such as 'smoking first thing in the morning', 'smoking in a public place', 'smoking last thing in the day'.
Options range from Never $=5$, Sometime $=4$, Often 3, Very Frequently $=2$, and Always $=1$. The scale was subjected to rigorous validation procedures, including content validity, concurrent validity, convergent validity, and discriminant validity. The scale also displayed high degree of homogeneity when subjected to factor analysis as all items loaded significantly on one factor. A coefficient of internal consistency of .89, using the Cronbach's Alpha, was obtained for the scale. Additionally, there were open-ended questions on when respondents first smoked (smoking debut), type of substance (s) smoked, and current substance use (number of sticks/wraps per day).

\section{Procedure}

The cross-sectional survey was conducted within Ago-Iwoye metropolis (the host community of Olabisi Onabanjo University). Snowballing technique was used to administer questionnaire to smoking student-patrons of two popular 'joints' (relaxation centers) in the town. Two barmen (one from each center) and two regular patrons of the centers (students of the lead author) helped in the administration of the questionnaire. The study satisfied the ethical requirements of Olabisi Onabanjo University. Patrons of these relaxation centers who were below the age of 18 and those who were not current smokers were excluded from the study. Informed consent was implied by the voluntary acceptance, completion and return of the questionnaire. Respondents' anonymity was guaranteed by asking them not to write their names or other identification on the research materials. Two hundred and fifty copies of the research questionnaire were administered over an eight-week period, out of which 230 copies were returned with usable data, thus representing a response rate of $92 \%$.

\section{RESULTS}

Table 1 presents the analysis of participants' responses to the question, 'What type of substance do you smoke?' Majority of 
Table 1: Gender differences in types of substance smoked, average daily consumption and onset of smoking.

\begin{tabular}{lcccccc}
\hline \multicolumn{1}{c}{ Smoking } & \multicolumn{2}{c}{ Males } & \multicolumn{2}{c}{ Females } & \multicolumn{2}{c}{ Total } \\
& $\mathbf{n}$ & $\mathbf{\%}$ & $\mathbf{n}$ & $\mathbf{\%}$ & $\mathbf{n}$ & $\mathbf{\%}$ \\
\hline Type of substance smoked & & & & & & \\
Cigarette & 102 & 74.45 & 73 & 78.50 & 175 & 76.09 \\
Marijuana & 17 & 12.41 & 12 & 12.90 & 29 & 12.61 \\
Cigarette \& Marijuana & 15 & 10.95 & 6 & 6.45 & 21 & 9.13 \\
Others & 3 & 2.19 & 2 & 2.15 & 5 & 2.17 \\
\hline Daily number of sticks smoked & & & & & & \\
$\mathbf{1 - 5}$ & 16 & 11.68 & 8 & 8.60 & 24 & 10.43 \\
$\mathbf{6 - 1 0}$ & 74 & 54.01 & 53 & 56.99 & 127 & 55.22 \\
$\mathbf{1 1 - 1 5}$ & 38 & 27.74 & 24 & 25.81 & 62 & 26.96 \\
$\mathbf{1 6 +}$ & 9 & 6.57 & 8 & 8.60 & 17 & 7.39 \\
\hline Onset of smoking (age) & & & & & & \\
Before 15 years & 85 & 62.04 & 51 & 54.84 & 136 & 59.13 \\
Between 16 to 20 years & 41 & 29.93 & 32 & 34.41 & 73 & 31.74 \\
After 20 years & 11 & 8.03 & 10 & 10.75 & 21 & 9.13 \\
\hline
\end{tabular}

participants $(76 \%)$ reported that they smoked cigarette only, $12.61 \%$ reported that they smoke marijuana only, $9.13 \%$ reported that they smoked both cigarette and marijuana, while the remaining $2.17 \%$ were not specific in the substances they smoked. Gender analysis of types of substance smoked showed that 102 (72\%) of the male respondents smoked only cigarette, 17 (12.41\%) smoked only marijuana, 15 (10.95\%) smoked both cigarette and marijuana, while 3 $(2.19 \%)$ were not specific in the substance they habitually smoked. Of the female respondents, $73(78.49 \%)$ reported smoking only cigarette, $12(12.90 \%)$ smoked only marijuana, $6(6.45 \%)$ smoked both cigarette and marijuana, while 2 $(2.15 \%)$ were not specific.

Participants were also asked to indicate, on the average, their rate of smoking per day. As shown in Table 1, 16 (11.68\%) of male respondents and $8(8.60 \%)$ of their female counterparts smoked between 1- 5 sticks per day; $74(54.01 \%)$ of males and $53(56.99 \%)$ of females smoked between 6 and 10 sticks per day; $38(27.74 \%)$ of males and $24(25.81 \%)$ of females smoked between 11 and 15 sticks per day; while $9(6.57 \%)$ of males and $8(8.6 \%)$ of females smoked 16 or more sticks per day. Combined, $34.35 \%$ (one-thirds) of the participants smoked more than 10 sticks per day. Regarding onset of smoking, results as shown in Table 1 indicated that $62 \%$ of male student smokers and $54.84 \%$ of their female counterparts had started smoking before age 15 years as against $8.03 \%$ males and $10.75 \%$ females who started smoking after age 20years.

We hypothesized that male students would report higher on smoking habit than female students. A t-test for independent samples was performed to test the hypothesis. Summary of the results is presented in Table 2 .

Table 2: Summary t-test for independent samples comparing males with females on smoking habits

\begin{tabular}{llcccccc}
\hline Variable & Source & N & Mean & SD & df & t & p \\
\hline \multirow{2}{*}{ Gender } & Males & 137 & 59.28 & 13.2 & \multirow{2}{*}{228} & 3.83 & NS \\
& Females & 93 & 57.23 & 12.1 & & & \\
\hline
\end{tabular}


Table 3: Summary t-test for independent samples comparing Internals with Externals on smoking habits

\begin{tabular}{llllllll}
\hline Variable & Source & N & Mean & SD & df & T & p \\
\hline \multirow{2}{*}{ LOC } & Internals & 108 & 69.82 & 14.12 & 228 & 21.21 & 0.01 \\
& Externals & 122 & 52.22 & 11.31 & & & \\
\hline
\end{tabular}

As shown in Table 2, there was no significant gender-related difference on smoking habit among undergraduate students $\{t(2,228)$ $=3.83 ; \mathrm{p} \mathrm{NS}\}$. This indicated that both male and female undergraduate smokers had similar smoking habits. However, it could be observed that male students reported slightly higher (mean of 59.28) than female students (mean of 57.23) on smoking habit although the difference did not attain statistical significance.

To test our hypothesis that locus of control would significantly influence smoking habit, a t-test for independent samples was performed to compare the smoking habits of internals with that of externals. Result of the analysis is presented in Table 3. Results indicated that internals scored significantly higher on smoking habit than externals $\{t(2,226)=21.21$, $\mathrm{p}<0.05\}$. This implied that students with internal locus of control (mean of 69.82) reported significantly higher and relatively better smoking habits than smokers with external locus of control (mean of 52.22).

We also explored the influence of age of smokers on smoking habit. Although age was measured as a continuous variable in the study, it was dichotomized into two, using age 22years as the cut-off point. The two groups were then compared on smoking habit, using t-test for independent groups as presented in Table 4.

As shown in Table 4, there was no significant influence of age on smoking habit $\{\mathrm{t}(2$, $228)=-0.19 ; \mathrm{p} \mathrm{NS})$. A closer look at the Table indicated that respondents aged 22 years or below were not significantly different (mean of 58.30) from their counterparts aged 23 years and above (mean of 58.61). Age, therefore, did not make a significant difference in smoking habit among undergraduate students studied.

\section{DISCUSSION}

The study examined smoking habits of selected undergraduate students of a non-residential Nigerian university: patterns of smoking, types of substance being smoked, onset of smoking, gender differences and the role of locus of control in smoking habits. In the initial analyses that were performed, results showed that majority of respondents smoked cigarette while others smoked marijuana or both cigarette and marijuana. It was also found that about one-thirds of the students smoked at least 10 sticks of cigarette per daily. These findings support previous empirical evidence (e.g. CDC, 2007; 2010a; Glantz, et al., 1995) that there is a high level of smoking among university students. Results also indicated that most respondents started smoking before 15 years of age. This latter finding implies that there may be other pervasive influences on smoking behaviour before a student enters the university, since most university students in Nigeria enter the university after age 15 years. Consistent with Stanton (1992) who found that

Table 4: Summary t-test for independent samples showing age difference on smoking habit

\begin{tabular}{llcccccc}
\hline Variable & \multicolumn{1}{c}{ Source } & N & Mean & SD & df & T & p \\
\hline \multirow{2}{*}{ Age } & 22yrs or less & 108 & 58.30 & 11.13 & 228 & -0.19 & NS \\
& 23 yrs or more & 122 & 58.61 & 13.34 & & & \\
\hline
\end{tabular}


most smokers begin during adolescence or early adulthood and that smoking has elements of risk-taking and rebellion, coupled with the presence of high-status models and peers, which often appeal to young people; results of the present study implied that students had probably acquired the smoking habits from peers, mass media and other influences before entering the university, and such influences should be the focus of preventive intervention among young people.

There was no statistically significant difference in smoking habit between male students and their female counterparts. Although this finding is in contrast with DiFranza et al.'s (1996) and Guindon and Boisclair (2003), it is consistent with recent findings indicating that the gender gap is declining with younger age (WHO, 2001; CDC, 2001). The finding is also consistent with recent findings in developed countries where smoking rates for men have peaked and have begun to decline while for women they continue to climb (Peto, Lopez, Boreham, Thun, 2006; WHO, 2002). This could be an indication of new dimensions in drug use among undergraduate students since males students were, hitherto, known to smoke and abuse psychoactive substances more than females. Age did not significantly influence smoking habit of students although. This implies that smoking habit is not a function of age and that other factors should be looked into for explanation of smoking behaviour. However, it is possible that the age difference was not significant because of the composition of the sample in the present study (participants were aged between 20 and 30years). Perhaps the age difference could have been significant had people below age 15 years been included in the study and compared.

The significant influence of locus of control on smoking behaviour is consistent with findings in previous studies (Booth-Butterfield, Anderson, \& Booth-Butterfield, 2000; Hogson, 2001) that individuals with external locus of control tend to engage more in health-impairing habits and behaviours than those with internal locus of control. Externals' belief that other influences outside of themselves control their lives' outcomes make them engage in healthimpairing behaviours, hoping that luck or fate would work in their favour. Internals, however, are known to hold their fate in their hand (Craig et al., 1984) and thus have a tendency to be more cautious and minimize engagement in health-impairing habits (Hogson, 2001).

The implication of these findings is that smoking cessation campaigners and other stakeholders should take locus of control into consideration in designing intervention programmes by impressing it on people that they are the architects of their own fate. Parents should also impress it upon their children early in life a man determines, by his actions and (or) inactions, most of his life's outcomes. Provision of psychological intervention to students in form of counseling, skill-building programmes and enlightenment programmes from time to time is strongly recommended. Enlightenment programmes devoid of stigmatization should be carried out in most of the relaxation centers located in host communities of universities. We also recommend that researchers should carry out more studies on this subject matter with a view to throwing more light on smoking among students and young people. This becomes particularly germane when the limitations of the present study (such as the cross-sectional nature of the study which made it impossible to infer causality, other potential predictor variables not incorporated, the relatively small sample size, etc.) are taken into consideration.

\section{REFERENCES}

Berlin, I., Singleton, E. G., Pedarriosse, A. M., Lancrenon, S., Rames, A., Aubin, H. J., \& Niaura, R. (2003). The Modified Reasons for Smoking Scale: Factorial Structure, Gender Effects and Relationship with Nicotine Dependence and Smoking Cessation in French Smokers". Addiction, 98 (11), 1575-1583.

Booth-Butterfield, M., Anderson, R., \& BoothButterfield, S. (2000). Adolescents' Use of Tobacco, Health Locus of Control, and 
Self-Monitoring. Health Communication, $12,137$.

Campaign for Tobacco-Free Kids. (2009). How Parents Can Protect Their Kids from Becoming Addicted Smokers. Washington: Campaign for Tobacco-Free Kids.

Centers for Disease Control and Prevention (2001). Surgeon General's Report: Women and Smoking. Retrieved: http://www. cdc.gov/tobacco/data_statistics/women. htm. 01-03- 2009.

Centers for Disease Control and Prevention (2002). Cigarette Smoking-Attributable Morbidity in the United States. Morbidity and Mortality Weekly Report, 52(35), 842-844.

Centers for Disease Control and Prevention. (2007). Best Practices for Comprehensive Tobacco Control Programs. Atlanta: U.S. Department of Health and Human Services, Centers for Disease Control and Prevention, National Center for Chronic Disease Prevention and Health Promotion, Office on Smoking and Health.

Centers for Disease Control and Prevention (2008). Smoking-Attributable Mortality, Years of Potential Life Lost, and Productivity Losses in the United States, 20002004. Morbidity and Mortality Weekly Report, 57(45), 1226-1228.

Centers for Disease Control and Prevention (2010a). Tobacco Use Among Middle and High School Students in the United States, 2000-2009. Morbidity and Mortality Weekly Report, 59(33), 10631068.

Centers for Disease Control and Prevention (2010b). Vital Signs: Current Cigarette Smoking Among Adults Aged $\geq 18$ YearsUnited States, 2009. Morbidity and Mortality Weekly Report, 59(35), 1135-40.

Craig, A. R., Franklin, J. A., \& Andrews, G. (1984). A Scale to measure Locus of Control. British Journal of Medical psychology, 57 (2), $173-180$.

Danklefs, S. (2004). The Relationships of Health Locus of Control, Health Value, Self-Efficacy, and Acculturation Status to
General and Specific Health Risk Behavior among Latino Adolescents. Dissertation Abstracts International: Section B: The Sciences \& Engineering, 64, 9-B, 4665

DiFranza, J.R., Savageau, J.A., \& Aisquith, B.F. (1996). Youth Access to Tobacco: The Effects of Age, Gender, Vending Machine Locks, and "It's the Law" Programs. Journal of Public Health; 86, 221-224.

Gilma, S. L., \& Xun, Z. (2004). Smoke: A Global History of Smoking. London, UK: Reaktion Books.

Glantz, S.A., \& Parnley, T.A., \& Mandel, L.L. (1995). Since school Based Tobacco Prevention Programs Do Not Work, What Should We Do? Journal of Adolescent Health, 59, 258-62.

Guindon, G. E., \& Boisclair, D. (2003). Past, Current and Future Trends in Tobacco Use. Washington DC: The International Bank for Reconstruction and Development / The World Bank. Retrieved: http:// www1.worldbank.org/tobacco/pdf/Guindon. 22-03-2009

Hawkins, J.D., Catalano, R.F., \& Miller, J.Y. (1992). Risk and Protective Factors for Alcohol and Other Drug Problems in Adolescence and Early Adulthood: Implications for Substance Abuse Prevention. Psychology Bull, 12, 64-105.

Hodgson, C. (2001). Health Locus of Control, Perception of Risk, and Risk-Taking Behavior in older Adolescents. Adolescents, 61, 46-50.

Johnston, L. D., O’Malley, P. M., Bachman, P. M., \& Schulenberg, J. E. (2009). Monitoring the Future: Smoking Continues Gradual Decline Among U.S. Teens, Smokeless Tobacco Threatens a Comeback. Ann Arbor (MI): University of Michigan News Service.

Lau, R.R. (1982). Origin of Health Locus of Control Beliefs. Journal of Personality and Social Psychology, 42, 322-334.

Melby, J.N., Conger, R.D., \& Conger, K.J. (1993). Effects of Parental Behavior on Tobacco use by Young Male Adolescents. Journal of Marriage and Family; 55, 439-454. 
Ogden, J. (2003). Health Psychology: A Textbook (2 $2^{\text {nd }}$ Edition). Buckingham: Open University Press.

Parkin, C., Fairweather, D. B., Shamsi, Z., Stanley, N., \& Hindmarch, I. (1998). The Effects of Cigarette Smoking on Overnight Performance. Psychopharmacology 136 (2), 172-178.

Parrott, A. C., \& Winder, G. (1989). "Nicotine Chewing Gum and Cigarette Smoking: Comparative Effects Upon Vigilance and Heart Rate". Psychopharmacology 97 (2), 257-261.

Peto, R., Lopez, A. D., Boreham, J., \& Thun, M. (2006). Mortality from Smoking in Developed Countries 1959 - 2000: Indirect Estimates from National Vital Statistics. London: Oxford University Press. Retrieved: http://www.ctsu.ox.ac. uk/ tobacco/.pdf. 22-02-09.

Santi, S., Best, J., \& Brown, K.S. (1990). Social environment and smoking initiation. Int Journal of Addiction; 25, 881-903.

Shamsuddin, M., \& Abdul-Han., N.H. (2000) Smoking Behaviour on Family and Consequence in Adolescence. Psychology Journal of Social Behaviour, 20, 135-45.

Stanton, W. (1992). A longitudinal study of the influence of parents and friends on children's initiation of smoking. Journal of Applied Developmental Psychology 13, 423434. doi:10.1016/0193-3973(92)90010-F
Substance Abuse and Mental Health Administration (2010). Results from the $2008 \mathrm{Na}$ tional Survey on Drug Use and Health: National Findings. Rockville (MD): Office of Applied Studies.

Tyas, S., \& Pederson, L.(1998). Psychological Factors Related to Adolescent Smoking: A critical Review of Literature. Tobacco Control, 7, 409-420.

Wang, S. Q., Yu, J.J., \& Zhu B.P. (1994). Cigarette Smoking and its Risk Factors among Senior High School Students in Beijing, China, 1998. Tobacco Control, 3 , 107-114.

Wingand, J. S. (2006). Additives, Cigatette Design and Tobacco Product Regulation. Retrieved http://www.jeffreywingand. com/WHOFinal.PDF 14/02/2009

World Health Organization (2001). Women and the Tobacco Epidemic: Challenges for the $21^{\text {st }}$ Century. Geneva: World Health Organization.

World Health Organization (2002). WHO/ WHO Regional Office for the Western Pacific (WPRO) Smoking Statistics. Geneva: World Health Organization. Retrieved: http://www.wpro.who.int/media_centre/ fact sheets/fs 20020528.htm.01-012009.

World Health Organization (2008). WHO Report on the Global Tobacco Epidemic. Geneva: World Health Organization. 